\title{
LA DUALIDAD CAMPELLO-FAHS EN EL ESPACIO AGRÍCOLA DE AL-ANDALUS (ALICANTE, CASTALLA, PEDREGUER, MADRID)
}

Por

MIKEL DE EPALZA

El latinismo campu y sus derivados se encuentran abundantemente documentados en época árabe en toda la Península Ibérica. Álvaro Galmés de Fuentes ha estudiado particularmente el topónimo mallorquín Campos, en relación con el fenómeno general de la conservación de la -o final en el mozárabe valenciano y balear (1). Por otra parte, Joan Coromines ha definido ya el sentido espacial agrícola que acompaña a esa denominación: «...el sentit llatí ha quedat especialment en la vinculació toponímica, aplicat a la rodalia planera d'una ciutat: el Camp de Tarragona..., El Cam d'Elx, o altres esteses més estretes de terra plana (Camp de I'Arpa, rodal freqüentat per gent sospitosa, en els antics afores de Barcelona)." (2).

Aquí quisiéramos presentar una hipótesis de mozarabismos (latinismos de época árabe o, mejor, préstamos latinos en la lengua árabe de Al-Andalus) relacionados con tres diminutivos de este nombre, El Campello, El Campillo y El Campell, topónimos de origen denominativo de espacios agrarios dependientes de poblaciones de la provincia de Alicante: El Campello se encuentra en la Huerta y al Oeste de Alicante y en Castalla (con el plural Els Campells); El Campillo en Orihuela, San Miguel de Salinas y El Verger; El Campell, en Pedreguer (3).

Nuestra hipótesis fundamental es que son diminutivos latinos conservados en época árabe, en relación con el campo o zona agraria dependiendo de una población, que se tradujo en esa época por el denominativo al-faḥs,

(1) A. GALMES DE FUENTES, Dialectologia mozárabe, Madrid, 1983, 136-141

(2) J. COROMINES, Diccionari etimològic i complementari de la llengua catalana, Barcelona, 1983, il, 460.

(3) Los topónimos de la provincia de Alicante serán sacados de J. L. ROMÁN DEL CERRO - M. DE EPALZA, Toponimia mayor y menor de la provincia de Alicante. Listado por municipios, Alicante, 1983, donde se puede hallar en el listado del municipio correspondiente, cuya referencia se da siempre en este trabajo. 
equivalente semántico árabe de campo, en ese sentido espacial. Forma parte de los espacios peri-urbanos que dependen de las ciudades musulmanas (4). Este nombre árabe ha dado topónimos en la provincia de Alicante (Alfàs del $\mathrm{Pi}$, Finestrat, lbi...). Pero, lo que es más significativo, va acompañado muchas veces con el topónimo El Campello, con el que tiene, en nuestra hipótesis, una relación orgánica (campo-campillo), que permite fechar esa realidad dual en época árabe. Es el caso de Alicante, Castalla, Pedreguer y, para confirmarlo, Madrid en sus relaciones con la llanura del Jarama y sus afluentes el Henares y el Manzanares.

\section{Campello, latinismo de la lengua árabe de Al-Andalus}

El topónimo El Campello, al Norte de la Huerta de Alicante lahora municipio de El Campello, por petición oficial razonada del Ayuntamiento, en 1986, para cambiar la denominación anterior de Campello, que no era la tradicional), ha sido siempre considerado como un mozarabismo, es decir un latinismo que no viene de las dos lenguas románicas, el castellano y el catalán, que se instalaron en la zona después del siglo XIII (5). En catalán el latinismo hubiera dado campet y en castellano campillo, campito o campico, como diminutivos de campu. La conservación de la -o final es una característica del mozárabe o romance de Al-Andalus, que se conserva fosilizado $y$ bien diferenciado en zonas catalanohablantes, como son la Horta d'Alacant y la Foia de Castalla.

Esta diferenciación de las otras lenguas románicas de la Península permite fechar este denominativo de antes de la conquita cristiana del siglo XIII $V$, seguramente, de antes de la conquista musulmana del VIII, conservándose fosilizado (en época árabe se perdería probablemente la conciencia lingüística de su significadol durante el período árabe y el cristiano, hasta nuestros días.

Semánticamente, su significado es bastante claro para los romancehablantes, porque la terminación diminutiva latina -illus da adjetivos semejantes en todas las lenguas románicas. Pero el significado más preciso de este topónimo diminutivo se puede estudiar con más exactitud en los casos de estos topónimos de la zona de Alicante (6).

\section{Campillo, posible mozarabismo}

Es evidente que el denominativo Campillo, de la Huerta de Orihuela, que ha quedado registrado hasta nuestros días en una callejuela que sale del nú-

(4) Ver líneas principales en M. de EPALZA, "Un "modelo operativo" de urbanismo musulmánn, Sharq Al-Andalus. Estudios Árabes, Alicante, 2, 1985, 137-149, especialmente p. 139, cuyas nociones se amplían y precisan aquí.

(5) Ver M. SANCHIS GUARNER, Aproximació a la historia de la llengua catalana, Estella (Navarra), 1980. p. 94, y ALCOVER-MOLL, Diccionari català-valencià-balear, Palma de Mallorca, 1980, p. 896.

(6) M. J. RUBIERA - M. DE EPALZA, Los nombres árabes de Benidorm y su comarca, Alicante, 1985. pp. 38-39. 
cleo central de la ciudad, hacia la parte Norte de la Huerta, es más difícil de fechar en época árabe al igual que el Campillo de Cehegín, en la vecina región murciana (7). En efecto, el diminutivo -illo se encuentra en castellano en todas las épocas y puede ser que ese topónimo haya nacido en época muy posterior a los árabes. Pero un serie de argumentos convergentes permiten creer en la posibilidad, y hasta en la probabilidad, de que Campillo tenga el mismo origen cronológico que Campello, en Orihuela y en otras regiones de la Península.

En primer lugar, se puede explicar la diferencia fonética de las vocales -e y -i de Campello y Campillo por los diferentes superestractos del catalán y del castellano. El catalán, que no tiene diminutivo en -illo y sí en cambio la desinencia -ell, puede mantener muy fácilmente la vocal -e, en la zona catalanohablante de Alicante, Castalla, Pedreguer y Vall de Laguart (Campello. Campe/I). En cambio, en la zona muy castellanizada actualmente de Orihuela, especialmente en el caso de nombres rurales o de la calle donde se ha conservado el topónimo, la transición de la e a la $i$ se puede explicar muy fácilmente. Por eso, puede suponerse sin dificultad que el Campillo actual podría ser un Campello procedente.

Esta posibilidad queda reforzada por el hecho de que los diminutivos en -jllo son muy poco frecuentes en la toponimia de la zona de Alicante, sea castellanohablante o catalanohablante. El único topónimo significativamente abundante es Ventorrillo (5 topónimos), pero como se encuentra sobre todo en zona catalanohablante, se puede sospechar que se trata de una traducción oficiał (de los cartógrafos de los mapas militares), castellanizante, de los también muy abundantes Venta y Venteta. También se encuentra el diminutivo El Portillo, en la zona catalanohablante de Agres, que es castellanismo de El Portitxol (Novelda, Teulada), también castellanizado El Portichuelo (Coix), en zona castellanohablante. También en la zona castellanohablante de Sax y Elda encontramos unos topónimos con final en -illo: El Chorillo, Los Charquillos, El Regatillo. En la zona castellanohablante de Orihuela se encuentran Horchi1lo, Horchillos (Orihuela), Monecillo (Granja de Rocamora) y El Molinillo (Jacarilla). No es mucho, al lado de otras formas de diminutivos como los que estudiamos: catalanes como Campet (Agost, Alicante, Alcosser, Camp de Mirra, Novelda, Petrer, Sant Joan d'Alacant) o castellanos como El Campico de los Moros (Redován, cerca de Orihuela).

Todo esto sin contar con que Campillo es también un antropónimo en Orihuela, que ha dado origen a un topónimo: Camino del Molino de Blas Campillo.

\section{Otros topónimos de la familia de El Campello}

La denominación latina campu ha dado, como ya se ha dicho, muchas palabras y no pocos topónimos de la región de Alicante. Algunos se encuen-

(7) Ver F. GÓMEZ ORTIN, "Después de Begastris: el misterioso Alquipir desvelado fidentifica una ciudad árabe en Cehegín)", Begastri, Murcia, 1984, 149-153. 
tran emparentados muy directamente con El Campello y podrían tener el mismo origen mozárabe. Hay otros, por el contrario, que manifiestan un origen totalmente diferente, de epoca cristiana catalanohablante y castellanohablante, y confirman así por contraste la identidad mozárabe del topónimo El Campe/lo. Finalmente, se puede comparar ese topónimo con otros que tienen la misma terminación o muy semejante.

En zona catalanoparlante, se encuentra el topónimo El Campell (Pedreguer, La Vall de Laguart). Podría ser el mismo El Campello, con caída de la vocal final, por influencia de la desinencia -ell del catalán. Ya volveremos más adelante sobre estos topónimos. Hay que advertir que el Campell de La Vall de Laguart se encuentra en una zona montañosa muy aislada, propicia a conservadurismos toponímicos, como éste o su vecino Benimantell, cuya apariencia árabe es muy discutible (8).

La dualidad Campello-Campillo se encuentra en los plurales: Els CampeIlos al lado de El Campello, en la zona catalanohablante de Castalla (por otra parte, flena de mozarabismos, por su aislamiento geográfico); Los o Els Campillos, en la zona limítrofe del catalán y del castellano, en Crevillente, donde hay también un Campo del Moro, como en Redován, cerca de Orihuela. Es evidente que los Campo de la toponimia alicantina, aunque estén localizados en zonas catalanohablantes, pueden ser modernas castellanizaciones, que nada tienen que ver con un mozarabismo con desinencia en -o. Pero sí que se puede sospechar ese origen en el Campos de lbi, también en la Foia de Castalla, si se pudiera aplicar el razonamiento de Galmés de Fuentes para el Campos de Mallorca: se tendría que probar que el topónimo tenía esa forma, en zona catalanohablante, poco tiempo después de la conquista cristiana del XIII (9)

Entre la Foia de Castalla y la Horta d'Alacant se encuentra en Agost la partida de Campellet, que parece un híbrido, de un diminutivo mozárabe -ello al que se ha añadido un diminutivo catalán -et. Al lado, hay una partida Campet, totalmente catalán. Esta vecindad y el hecho de que se trata de nombres de partidas, generalmente más conservadoras en toponimia, confirma la originalidad de los topónimos mozárabes dentro de un contexto lingüístico valenciano.

Unos cuantos topónimos de la zona alicantina tienen desinencias que aparentemente, se parecen a la de El Campello: Cavatello (Agres), Armanello (Benidorm), El Serallo (Ibi, Onil, ambos en la Foia de Castalla), El Negrello (Planes). Habría que estudiar cada caso para afirmar o negar ese origen mozárabe. Otros ejemplos. con la posible caída de la -o final, quizás, por influencia del catalán, serían todavía más problemáticos.

(8) M. J. RUBIERA - M. DE EPALZA, o. c., pp. 54-62

(9) Ver supra, nota (1). 


\section{Los Campello en relación con los Campo o Alfás (faḥṣ) de una población}

Ya se ha probado, con relativa certeza, el origen mozárabe del denominativo diminutivo El Campello y quizás también de muchos El Campillo o El Campell. Ahora conviene precisar un poco más su contenido semántico, que se puede conocer en primer lugar por la propia realidad denominada, en la región de Alicante. Pero también sus relaciones con otros topónimos vecinos permiten unas precisiones semánticas que dan a conocer mejor la realidad del espacio agrícola de los alrededores de las ciudades o poblaciones islámicas, aunque la denominación venga hipotéticamente de antes de los musulmanes.

Campello viene de "campo», especialmente relacionado, en toponimia, con la denominación de una región o zona, según la cita ya mencionada de Coromines (10). La continuidad de este sentido, desde el latín a nuestros días, hace muy probable que tuviera la misma carga semántica en los topónimos denominativos de época árabe.

Ahora bien, el hecho de que esté en forma de diminutivo supone una realidad más pequeña que un campo normal o más pequeña que un campo situado en su vecindad, que va a ser nuestra hipótesis.

Es verdad que el bajo latín utilizaba mucho los diminutivos, en los topónimos. Buena prueba de ello es el nombre de muchas ciudades hispanas cuando llegaron los árabes: Orihuela, Valentula, Toleitula, etc. (11), en proceso paralelo al de denominativos norteafricanos de idéntica estructura, aún conservados como Sbeitla (Sufaitula, en Túnez) o ya desaparecidos como lcosomul, antiguo poblado donde se asentaría la moderna Argel (Al-yazâ'ir o «las islasi) (12). Pero también puede suponerse que los Campello o "pequeños camposmeran así denominados er relación con un gran Campo o zona llana y agraria relacionada con una ciudad o población.

Esta realidad puede suponerse en el caso de la zona de Alicante. El Campo o Huerta de Alicante (que no hay que confundir con las huertas periurbanas, junto a las murallas, que corresponderían a la actual zona de la Rambla Méndez Núñez o la antigua Huerta de San Franciscol comprende una amplia zona al norte de la ciudad, entre montañas, terrenos áridos y el mar. Dentro de este espacio, El Campello es un espacio reducido, separado del conjunto del Campo por el Riu Sec o Riu Monnegre, que desemboca en el mar después de atravesar la llanura alicantina durante unos cuantos kilómetros en un tajo bastante profundo, que separa muy claramente el "campello" del resto del "Campo". Se podría deducir de esto que El Campello es un pequeño Campo, al lado del grande.

\footnotetext{
(10) Ver supra, nota (2)

(11) M. J. RUBiERA MATA, "Valencia en el pacto de Tudmîr", Sharq Al-Andalus. Estudios Árabes, Alicante, 2. 1985, 19-120

(12) E. BEN JAAFAR, Les noms dé lieux de Tunisie, Túnez, 1985, p. 39.
} 
La hipótesis parecería también váfida para el Campillo de Orihuela, localizado en la orilla izquierda del río Segura, una vez pasada la ciudad, entre la montaña y el río, donde se encuentra ahora el palmeral. Es también una zona llana y cultivada, que estaría separada, por una torrentera, del más amplio Campo cultivado, al Norte de la ciudad y en dirección de Redován, después del Campillo.

Pero la estructura dual Campo-Campello se da muy clara en los casos de Castalla y de Pedreguer. En Castalla El Campello es una partida rural, llana y cultivable, separada por el río Verd o de Castalla de otra partida, mucho más grande, pero llana y cultivable, llamada El Alfàs («campo» en árabe). En Pedreguer se da la misma dualidad entre la partida de El Campell y la de El Alfàs, una más pequeña que la otra y separadas por el arroyo llamado Riu Bo. Es la misma dualidad que habiamos encontrado en Alicante, donde podemos suponer con mucha probabilidad que el Camp u Horta se llamaba también en época árabe Alfás, ya que existe aún la denominación toponímica en la acequia del Alfàs. Estaría separada de El Campello por el Riu Sec o Monnegre.

El topónimo Alfás (en catalán Alfàs) viene del árabe al-faḥ̦, que designa a una zona agrícola relacionada con una población y - fosilizada también en árabe actual- - da todavía topónimos en el Mágreb. Al-Fahs o Pont du Fahs es capital de una rica zona agrícola junto al río Miliana, a $60 \mathrm{kms}$. al Sur de Túnez, llamada también «llanura del Fahș ar-Riyâh» («alfás de los vientos"), famosa desde época romana por su fertilidad atestiguada por la próspera ciudad de Tuburbo Maius. Esa llanura es el fahș de Túnez por excelencia, que empieza a unos $20 \mathrm{kms}$. de la capital, después de una zona de montículos yermos y de salinas. Fahș era una palabra viva en el árabe clásico medieval, como se ve en el geógrafo Al-Bakri (s. XI), pero está fosilizada actualmente en topónimos, como en diversos casos tunecinos y en la zona Sur de Tánger en Marruecos, auténtico fahș o territorio rural dependiente de la ciudad (14). Tengo referencia, indocumentada, de otro fahș cerca de Trípoli de Libia.

Según Groom (15), la palabra fahss ha dado topónimos en árabe con el significado de «terreno llano; una amplia y abierta zona. Un lugar deshabitado. Un lugar que ha sido dug o agujereadon. Más cerca de la realidad de AlAndalus, Dozy (16) recoge la traducción «llanura, campon, a partir del Vocabulista (campus) y de Pedro de Alcalá («canpo raso como vega, canpo que se labra"). La Vega de Granada es quizás el ejemplo más significativo en Al-

(14) E. BEN JAAFAR, o. c., pp. 28, 100, 177. A. BOULIFA, Mutations et organisation d'un espace périurbain: le Fahs de Tanger et ses bordures, Poitiers, 1986, 352 pp. y cpropiété foncière citadine dans le Fahs de Tanger (Répartition et mode de faire-valoirn, Revue de la Faculté de Lettres, Tétuán, 1. $140711986,59-75$.

(15) N. GROOM, A Dictionary of Arabic Topography and Placenames, Beirut, 1983, pp. 81, 297.

(16) R. DOZY, Supplément aux dictionnaires arabes, Leyde, 1881, reimpr. Beirut, 1968. 11, 243. 
Andalus, documentado en el siglo XI (17), pero también corresponde a un espacio agrícola al Sur de Sevilla (18) y en Extremadura (19).

Fahș es una palabra árabe que no ha pasado a las lenguas romances, lo que permite fechar perfectamente su vitalidad como topónimo: es de época árabe indudable y no puede ser un arabismo que se hubiera puesto a partir de una de las lenguas románicas que lo habrian asimilado. No se ha de confundir, por otra parte, esta palabra árabe con el arabismo denominativo alfoz, que siguió vivo en las lenguas romances y que viene del árabe: «distrito, comarca que depende de una ciudad o castillo, del ár. háuz "comarca", derivado de hâz "allegar", "poseer"..." (20).

Fahs ha dado en Al-Andalus numerosos topónimos, atestiguados por las fuentes árabes $y$, a veces, conservados en la toponimia actual: Acialcázar, Fajalanza, Moratalaz, Fazali, Zafalretama, etc.

Así nos encontramos que el binomio Alfás-Campello que se hallan físicamente colindantes y nunca yuxtapuestos en Alicante, Castalla y Pedreguer (y veremos que también en Madrid) confirman, por una parte, la fechación de El Campello como mozarabismo o latinismo de época árabe, pero por otra nos permiten definir mejor su relación mutua (de mayor a menor, ya que "alfấs» sería una traducción del "campo» latino) y su naturaleza idéntica, de campo llano y cultivado, dependiente de una ciudad. En época árabe se traduciria el topónimo denominativo Campo por Fahș, por ser el más importante y significativo, quedando el Campillo fosilizado en mozarabismo, ya que su traducción al árabe como diminutivo es fonéticamente difícil e inusual (fuhayș). En época cristiana fue el Alfás el que quedó fosilizado y semánticamente opaco, recuperando Campello su significado, gracias a su parentesco con las denominaciones paralelas de las nuevas lenguas romances de los conquistadores: guardaría la forma mozárabe de Campello en algunos casos o se adaptaría a las nuevas lenguas en otros, en forma de Campell catalán o de Campillo castellano.

Se pueden sacar, pues, tres conclusiones de este análisis lingüístico, toponímico y geográfico:

1. El binomio campo-campello es pre-árabe, para designar a dos zonas llanas, cultivables y no muy alejadas de poblaciones, una de ellas más

(17) E. LEVI-PROVENCAL: "Deux nouveaux fragments des "Mémoires" du roi zîride "Abd Allâh de Grenade", Al-Andalus, Madrid, VI, 1941, 377-399. E. LEVI-PROVENCCAL - E. GARCÍA GÓMEZ, El siglo $X$ en $1 .{ }^{\circ}$ persona. "Momorias" de "Abd Allâh, último rev de Granada, destronado por los almorávides (1090), Madrid, 1980, p. 88.

(18) R. VALENCIA, "Alcalá de Guadaira en la Alta Edad Media: la historia de Qalat Chabir", Actas de las I Jornadas de Historia de Alcalá de Guadaira (Sevilla), Sevilla, 1987, 31-43.

(19) M. VELHO, "A incursâo de Tâšfîn ibn "Alî a Fahș al-Șabâb», Is/âo e Arabismo na Península Ibérica, Evora, 1986, 331-336

(20) J. COROMINES - J. A. PASCUAL, Diccionario critico etimológico castellano e hispánico, Madrid, 1980. I. $157-158$. 
grande y otra más pequeña, separadas normalmente por un accidente físico - en particular un río--, pero consideradas como un mismo espacio geográfico.

2. Este binomio perdura en época árabe, con la traducción de campo por fahs. Como la palabra árabe no suele formar diminutivos en toponimia o como no había en esa época una conciencia de la separación y pequeñez del Campello, este nombre se conserva en mozárabe sin traducirlo, durante la época musulmana, en muchos sitios, conservándose también en época cristiana posterior o adaptándose a las nuevas lenguas romances, castellano o catalán, hasta nuestros días.

3. ${ }^{\circ}$ El nombre y la estructura dual aparecen claros en Alicante, Castalla, Pedreguer y probablemente en Orihuela. Es posible que el mismo fenómeno se pueda encontrar en otras zonas donde hay huellas toponímicas semejantes, que pueden documentar la presencia del binomio en época árabe y preárabe: El Campello, al Sur de la ciudad de Alicante $(21)$; los Campell y Campellet de La Valle de Laguart y Agost; los Alfás de Alfàs del Pi, Finestrat y sobre todo $\mathrm{Ibi}$, relacionado con los topónimos de Castalla ya mencionados.

\section{La confirmación del binomio: fahṣ y campillo de Madrid}

Para comprender mejor el binomio onomástico y la estructura agrícola y geográfica que ese binomio revela en la región de Alicante - y probablemente en otras regiones de la Península lbérica, del Mágreb y del mundo árabe en general - , puede resultar útil compararlo con ese mismo fenómeno en la región de Madrid, donde ya en 1949 el arabista, académico e investigador Jaime Oliver Asín había señalado y estudiado diversos topónimos derivados de fahș (22). No hay que olvidar que la zona de Madrid-especialmente el valle del Jarama y sus afluentes el Henares y el Manzanares - había sido profundamente romanizada, por ser paso de la comunicación Zaragoza-Mérida $y$ de los caminos transversales N.-S. de los pasos de Toledo con la Meseta Norte.

También los árabes le concedieron una singular importancia de Marca Media (At-tagr al-wașiț), entre Medinaceli y Talavera, con centro en Toledo. A fines del siglo IX el emir omeya de Córdoba Muhammad I creó dos impresionantes ciudades-fortalezas que protegieran la región y sus accesos: Talamanca del Jarama y Madrid (23). Madrid, ciudad y fortaleza árabes, por su

(21) Ver E. GARCIA GARIJO, "La Alcoraya: un espacio histórico agrícola y vial», Sharq Al-Andalus. Estudios Árabes, 4, 1987 (en este volumen)

(22) J. OLIVER ASÍN, "Estudios de toponimia madrileña. "La Salmedina" y "Vaciamadrid" ", Revista del Archivo, Biblioteca y Museo del Ayuntamiento de Madrid, 3, 1948, 1-8, y Historia del nombre "Madrid", Madrid, 1959, p. 38.

123) M. J. RUBIERA, "Madjrît", Encyclopédie de I'lslam, Leiden, 2. "ed., vol. V, fasc. 95-96, 1985, $1103-$ 1104. Agradezco a la profesora Rubiera numerosas orientaciones sobre el Madrid árabe y su región. sobre lo que es especialista. Véase también B. PAVÓN MALDONADO, "Arqueologla y urbanismo medieval en Madrid», Awrăq, Madrid, VII-VIII, 1984-85, pp. 231-233 
gran importancia como centro de un sistema de organización de su espacio entorno, permite quizás comprender mejor unos fenómenos espaciales que también se repetirán a otras escalas en toda la península, en el período musulmán.

La dualidad fahs-campello se da claramente ya en la zona de San Fernando de Henares (llamada Torrejón de la Ribera, antes de Fernando VI, 1746). En la orilla izquierda del Jarama se encuentra el topónimo de una partida, Baciabotas, cuyo primer elemento (bacia) es una evolución del nombre árabe fahș, como demostró Oliver Asín (24) (el segundo elemento es indescifrable evidentemente asimilado fonéticamente a botas, nombre común). Esa partida se halla en un llano fértil - lo que corresponde a las características físicas de los demás fahṣ ya mencionados - y antes de que se junte el Henares al Jarama, también en la orilla izquierda. El Jarama separa a ese fahs de un topónimo El Campito, situado en la orilla derecha del río, en un meandro, y de la misma naturaleza llana y fértil que la zona de Baciabotas.

Tenemos aquí, por tanto, la misma dualidad, ya advertida en la región alicantina: el topónimo árabe fahss, sin el artículo al-porque va seguido de un determinante nominal, botas; corresponde a una zona llana y agrícolamente fértil, aunque no parece fuera irrigada en su totalidad, como las vegas periurbanas cercanas al río (los topónimos arabizados Albega, de Alcalá de Henares, sobre el Henares, y la Albega de Madrid, sobre el Manzanares); el que fahș no haya sido romanizado como nombre común, lo que permite fechar esa estructura agrícola como de época árabe; el que esté acompañado de un El Campito, de su misma naturaleza, llano y fértil, separado por un obstáculo natural claro, el río, y cuya denominación puede fecharse en época árabe precisamente por su vecindad con el arabismo fahș, de Baciabotas.

En El Campito vemos, evidentemente, una castellanización del diminutivo latino-mozárabe, que deja probablemente la terminación -ello para adoptar la final enteramente castellana -ito. la evolución castellanizadora es pues clara: El Campello - El Campillo - El Campito. Hay que tener en cuenta la fuerza lingüística del castellano y de su presión durante nueve siglos en una zona romanizada y fuertemente arabizada durante cuatro siglos, pero conquistada por los cristianos ya en 1083. De todas formas, quedan en la zona del valle del Jarama y sus afluentes varios El Campillo, que conservarían la forma de la etapa anterior de la evolución de El Campito. Se encuentran generalmente, de forma muy significativa, en zonas más aisladas $-y$ hay que suponer por eso más conservadoras - que El Campito de San Fernando de Henares, paso casi obligado entre Madrid y el camino de Aragón por Alcalá de Henares y Guadalajara.

Tres El Campillo se encuentran en la zona, como el de Orihuela: el de Alcalá de Henares, separado de su alfoz y de la Albega por el macizo y cuesta de Zulema (otro arabismo, de Sulaimán, el rey Salomón de la Biblia y del Co-

(24) Ver supra, nota (22) 
rán, a cuya famosa mesa del Templo se atribuye semejanza con la forma de esta meseta) (25); El Campillo de Arganda del Rey, amplia partida en alto, al Este y Sureste de la población; El Campillo de Rivas-Vaciamadrid, que por convivir con otro topónimo derivado de fahș (vacia) hay que estudiar más detenidamente.

El Campillo de Alcalá de Henares corresponde a la descripción general de esos denominativos - terreno llano y en alto, de secano y fértil--, pero no se ve ningún gran campo o fahs cercano, a no ser que se trate de la gran zona de la cuenca del Jarama - como se estudiará después - o de la relación con la zona urbana y periurbana de Alcalá de Henares. El Campillo de Arganda del Rey corresponde también a la descripción general - terreno llano, en alto, de secano, fértil-, pero parece un poco alejado, separado por el Barranco Jismeno, de otra zona quizás semejante, al norte, que tiene por centro la población significativamente llamada Campo Real. En esta región, un poco apartada de las vias de comunicación, quizás nos encontraríamos aún con el antiguo binomio en su forma pre-árabe campo-campillo, fechable en época árabe por el añadido Real, que puede ser un arabismo encubierto (riyâọ, "huerto, jardín») (26): sería, en época árabe, "campo del jardín". Se mantendría la denominación pre-árabe campo, sin traducirla a fahș, quizás porque la zona no tuvo una población suficientemente arabizada para esa traducción.

La relación de todos estos lugares y topónimos -Campo, Campillo, Campito, Fahs - con un hipotético campo común y sus relaciones con Madrid se estudiarán al final, después de analizar los lugares y topónimos más significativos de la zona del Jarama y sus afluentes: los fahș de Salmedina y Vaciamadrid y su vecino El Campillo.

La zona de Salmedina (fahș al-madîna, "campo de la ciudad", según demostración filológica documentada de Oliver Asín (27)) se encuentra en un ensanchamiento de la ribera izquierda del Manzanares, cuando sale del municipio de Madrid-Villaverde y pasa en valle llano, algo encajonado y seguramente fértil, por delante de Perales del Río, La Aldehuela, Casa de la Torrecilla y Casa Eulogio, hoy caseríos del municipio de Getafe, a su derecha, y con los sierra-acantilados de La Torrecilla y Las Torrecillas, en la orilla izquierda, al Norte. La Salmedina es calificada por Oliver, a partir de documentación medieval cristiana, como «una gran dehesa, con tierras de pan llevar, prados para pastos y sotos con abundante caza de conejos" (28). Se ve bien aquí que se trata de una zona llana y rica, de producción polivalente, aunque la traducción de fahș por "dehesa», ya atestiguada por Pedro de Alcalá a principios del siglo XVI («dehesa concejil»), acentúe su carácter ganadero, asumido después por Dozy en su diccionario l «pâturage possédé par indivis ou en com-

(25) M. J. RUBiera MATA, "La mesa de Salomón", Awrâq, Madrid, Ill, 1980, 25-31.

(26) M. J. RUBIERA, «Rafals y reales; ravals y arrabales; reals y reales», Sharq Al-Andalus. Estudios Arabes, Alicante, 1, 1984, 117-122.

(27) Ver supra, nota (22)

(28) J. OLIVER ASIN, «Estudios...», p. 2. 
mun») (29). Con cierta prudencia, para no hacer decir al término árabe más de lo que quiere decir, se puede admitir ese carácter también ganadero del espacio rural llano y de secano de los fahs árabes. Sería un espacio ganadero no acotado (frente a los raal-rafal en las huertas y los albacar en las fortalezas (30)1. Pero no hay que olvidar que esta denominación árabe viene acompañada del diminutivo referencial Campello (Campillo, Campito) y seguramente del latinismo Campo, con referencia a zona cultivada, evidentemente con agricultura cerealista extensiva, como se ve aún hoy en día en el fahṣ de Túnez $y$ en el de Tánger, ya mencionados. Puede haber además, acentuando ese carácter ganadero, una deformación de las fuentes, por la realidad cristiana medieval que, en la Meseta, inició un predominio cada vez mejor organizado de la ganadería sobre terrenos antes agrícolas. También puede haber superposición de instituciones cristianas al considerar que "concejil) (Pedro de Alcalá) es un concepto de propiedad catastral, como lo define Dozy («pastos poseídos en proindiviso o en común»). Lo que sí está claro es que se trata de un espacio rural que depende muy estrechamente de una ciudad o de un núcleo importante de población, aunque esté algo distante de la zona urbana o de las huertas periurbanas (Salmedina esta a unos $8 \mathrm{kms}$. de Madrid y Vaciamadrid a unos 201. Se podría deducir eso del probable paralelismo del emplazamiento de estos topónimos dobles en la zona de Alicante: los alfás dependen de Alicante, de Castalla, de Ondara o Pedreguer, de Altea, de Finestrat, de Orihuela. En la zona madrileña la dependencia está aún más clara, al tener la palabra fahș un determinativo urbano: fahs al-madîna ("campo de la ciudad»), fahș maýrịt ( «campo de Madrid») en los casos de Salmedina y Vaciamadrid, aunque también se daría en el caso de Baciabotas.

Salmedina está separado por un Congosto o garganta estrecha (quizás traducción del denominativo madíq en época árabe, como el topónimo del río de Gallinera, en la zona Norte de la provincia de Alicante, Almadic) de la zona de Vaciamadrid (fahș Maŷrît, según el estudio de Oliver Asín), también a orillas del Manzanares hasta su unión con el Jarama. El que este topónimo esté cerca de un El Campillo y que abra el campo a la gran llanura del Jarama o Campo de Arganda, viniendo de Madrid (sea por la carretera, actual N-ll de Madrid a Valencia, sea por el río Manzanares, como parece se hacía antiguamente) hace el estudio de este topónimo particularmente interesante, como confirmación final de esta investigación agronómica.

La relación entre Vaciamadrid (fahs Maŷrît, "Alfás o Campo de Madrid, según Oliver Asín) y su partida vecina El Campillo corresponde también al binomio encontrado en la región alicantina. El Campillo es un espacio agrícola de secano, más pequeño que el fahș de Madrid y en altura con respecto a éste, en las colinas-acantilados de Las Rivas del Jarama. Pero la abundancia de topónimos El Campillo en zonas periféricas de todo el conjunto del llamado

(29) R. DOZY, o. c., p. 243

(30) M. J. RUBIERA, "Rafals...", y M. DE EPALZA, "Funciones ganaderas de los albacares, en las fortalezas musulmanas"", Sharq Al-Andalus. Estudios Árabes, Alicante, 1, 1984, 47-54. 
ahora Campo de Arganda nos obliga a plantearnos en unos términos específicos la dualidad campo-campillo en esta zona.

El río Mazanares es el eje geográfico de la estructura espacial de los territorios dependientes de la ciudad de Madrid, ya en época árabe, porque la presencia de la palabra fahs así permite fecharlo, para Salmedina y Vaciamadrid, ya que era palabra semánticamente "opaca» para los conquistadores cristianos, que no podian dar ese nombre a un lugar al no figurar asimilado como arabismo en su lengua. Esa estructuración de los espacios agrícolas de Madrid se inicia al pie de la ciudadela o alcazaba de la ciudad, con la huerta periurbana o Albega. Siguiendo el cauce relativamente encajonado del Manzanares, venía el llano del "campo de la ciudad" o Salmedina (fahș al-madina), separado por el Congosto o estrechura del río del "campo de Madrid" o Vaciamadrid (fahṣ maýriț), ya casi en la desembocadura del Manzanares en el Jarama. Hasta aquí los tres arabismos atestiguan fehacientemente la fechación de época árabe de esta estructuración del espacio agrícola, confirmada con la presencia un poco más al Norte de otro fahș, el de Baciabotas, también a orillas del Jarama y en el eje vial Madrid-Alcalá-Guadalajara y, probablemente, también el de Madrid-Talamanca.

La vecindad de estos arabismos de los topónimos Campo (Mejorada del Campo, Campo Real, Campo de Arganda) y de los numerosos El Campillo de la zona nos lleva a emitir la hipótesis de que estas denominaciones latinas fueran preárabes, conservadas en época árabe y recuperadas como mozarabismos o como arabismos asimilados al castellano, respectivamente, en época romance cristiana. El preárabe Campo se habría conservado en época árabe, por débil presión de la arabización, que lo habría traducido a fahș sólo en las zonas más próximas a la ciudad y a sus vías de acceso, en los casos de Salmedina, Vaciamadrid y Vaciabotas.

Aqui, como en la región de Alicante, el binomio árabe fahş-campello permitiría fechar en parte el binomio campo-campillo, de suyo ucrónico al poder ser un latinismo de época preárabe, árabe y cristiano medieval. Podría afirmarse que toda la zona del Jarama, entre las desembocaduras del Henares y del Manzanares, formó un Campo (el actual Campo de Arganda), que generó numerosos El Campillo en espacios más pequeños en comparación con él $y$ en sus zonas periféricas, también en binomio con los fahș árabes.

Aunque se quiera, en algunos casos, hacer retrasar muy legitimamente el nacimiento de algún El Campillo a época cristiana postárabe, no podrá negarse la posibilidad de su existencia como mozarabismo, también en época árabe. La misma abundancia de Campillo en la zona indicaría hábito de esa denominación en el romance local. Al Norte de Madrid, la existencia de un El Campillo, zona agrícola y llana junto a Villalba, población documentada en la vía romana de Guadarrama, confirmaría probablemente el carácter de mozarabismo de esta denominación geográfica. 
Finalmente, la equivalencia latino-árabe campo-faḥș y su paralelismo en llanuras agrícolas magrebíes algo alejadas de las ciudades pero dependientes de ellas (alfás de Túnez y de Tánger) permiten pensar que el Campo de Arganda era considerado como una llanura rural agrícola-ganadera dependiente de una ciudad, quizás Compluto en época pre-árabe, Madrid en época árabe.

\section{Conclusión}

Este estudio nuevo y de conjunto, sobre los tres denominativos latinoárabes ya conocidos individualmente (campo-campillo-fahș), no sólo pretende estructurarlos semánticamente y precisar mejor la fechación histórica de su evolución y mutua relación. Pretende también aportar un mejor conocimiento a la naturaleza de los espacios agrícolas más estructuralmente dependientes de las ciudades árabes. Forma parte, por ello, del estudio del urbanismo musulmán, que, aún en su vertiente agraria y rural, depende de las ciudades, como todos los elementos de la civilización árabe-islámica, esencial y radicalmente urbana (31).

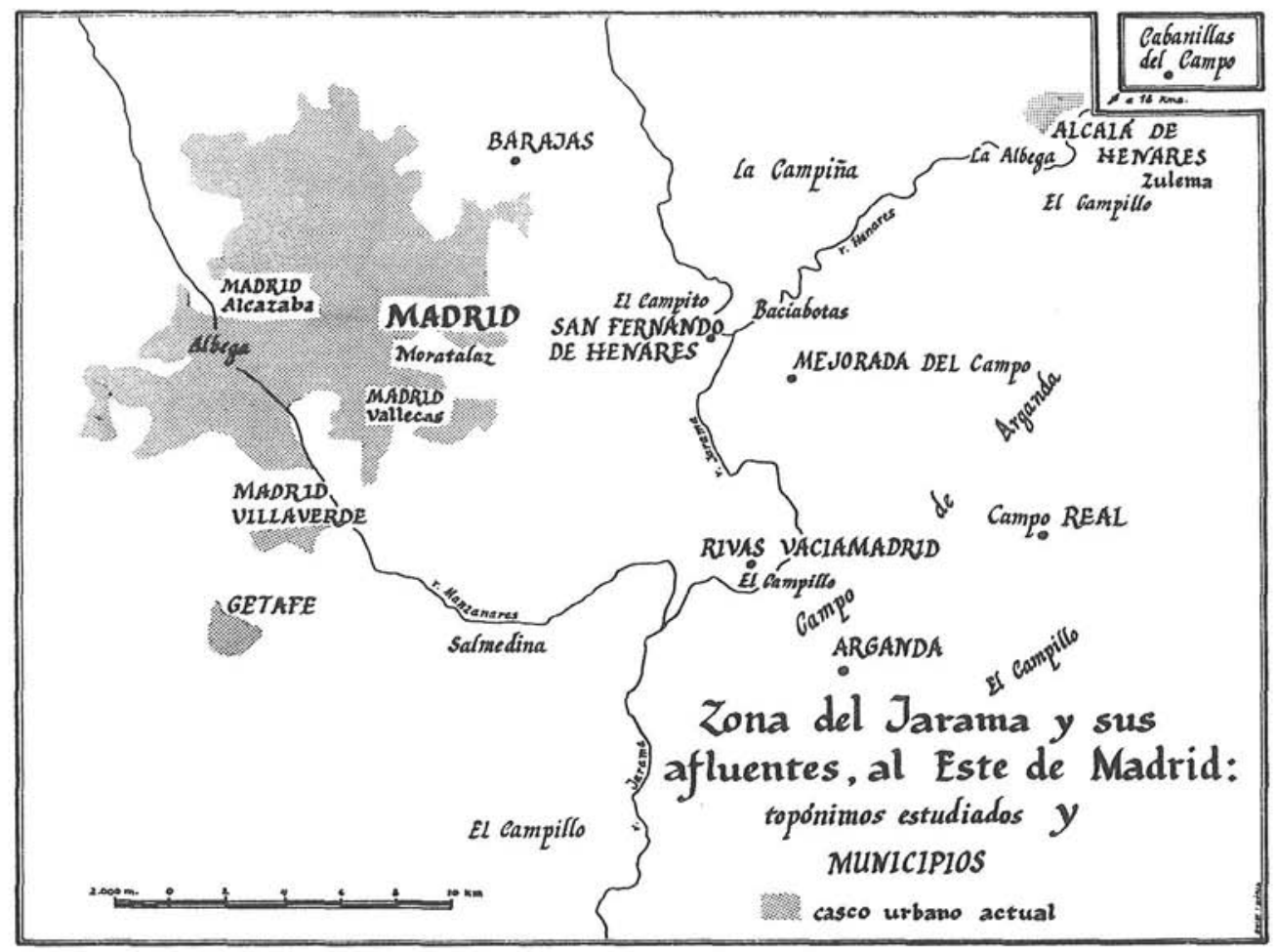

(31) Ver M. DE EPALZA, "Precisiones sobre instituciones musulmanas de las Baleares», Les Illes Orientals d'Al-Andalus, Palma de Mallorca, 1987, 73-87. 


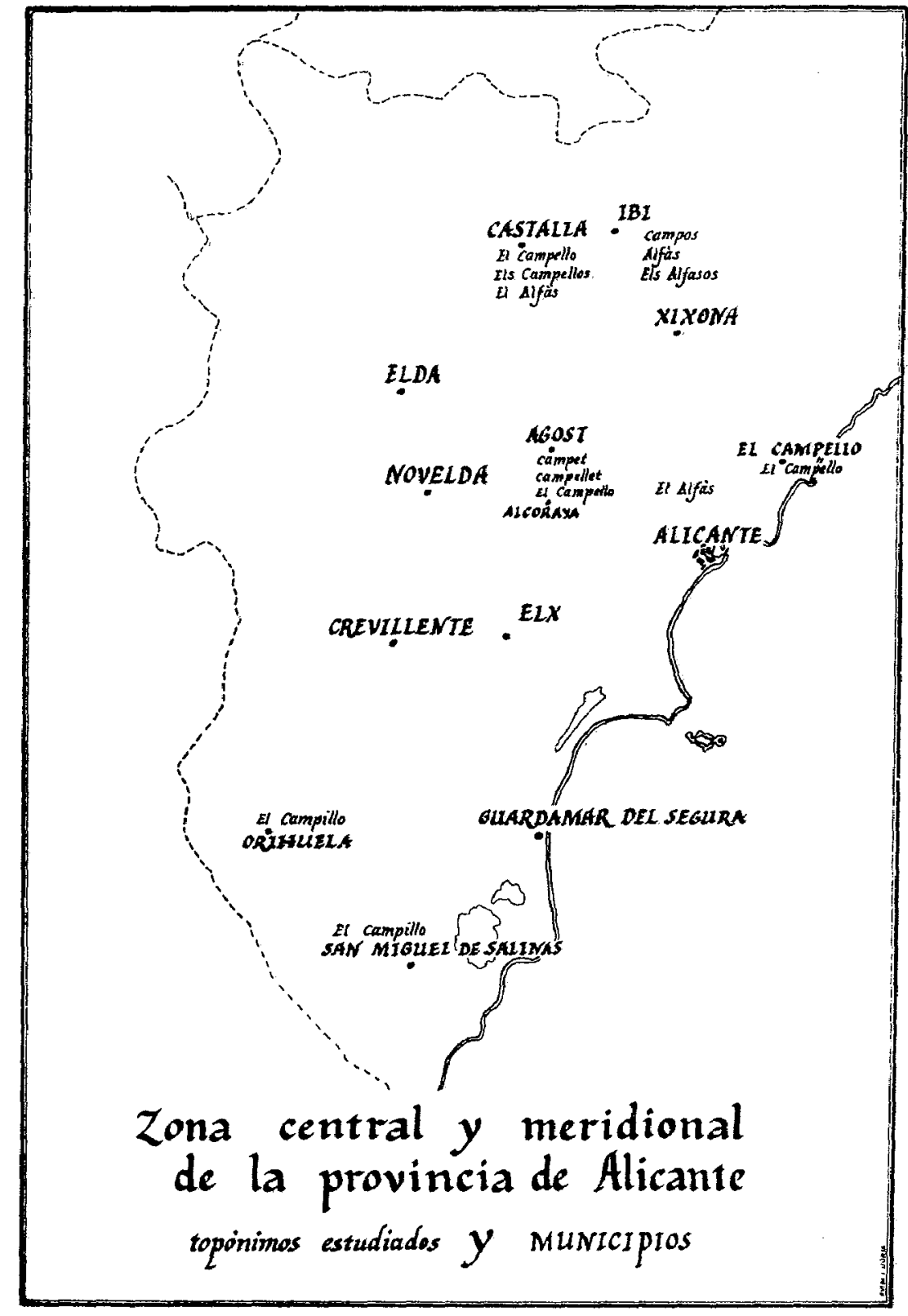




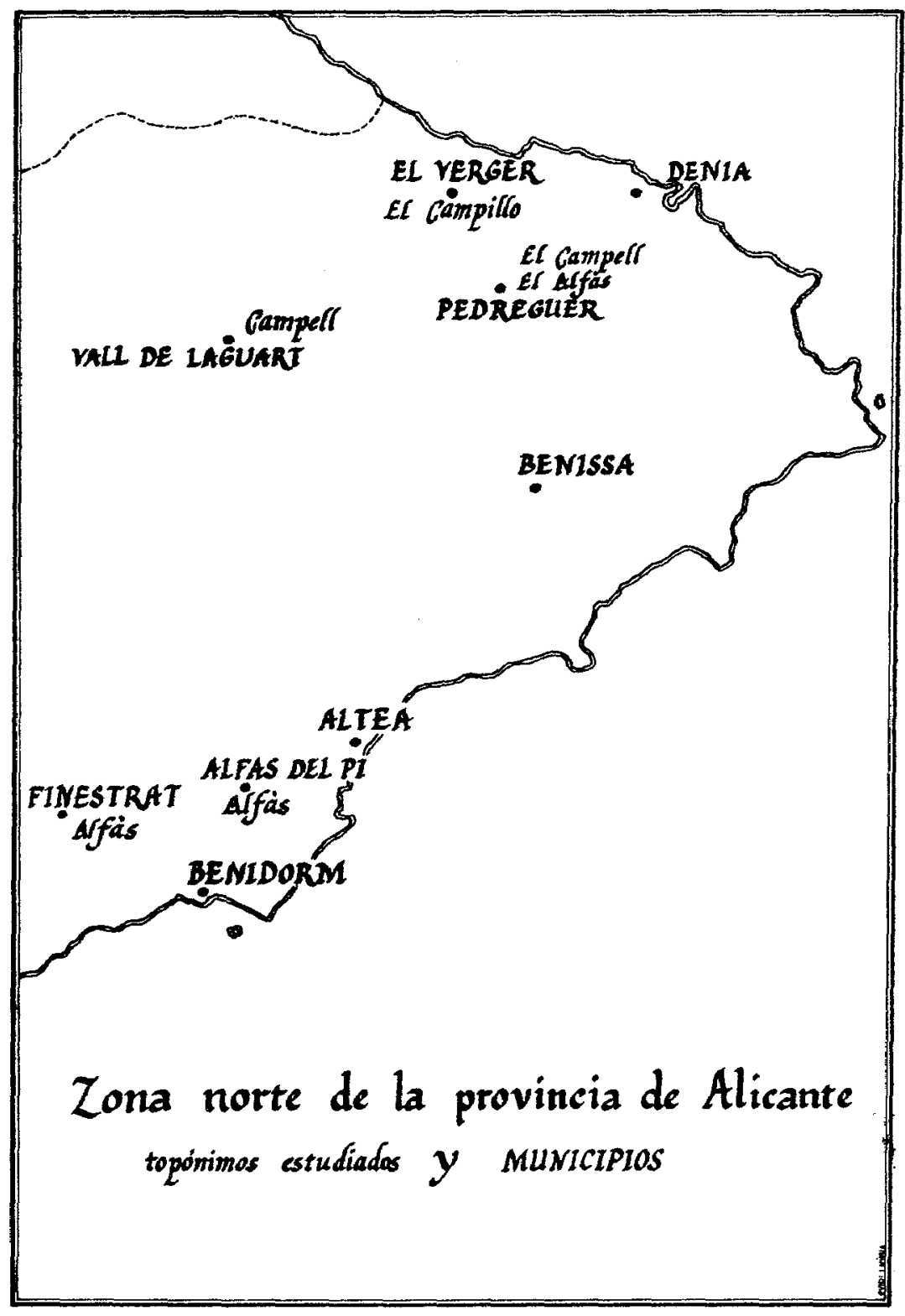

